Research Article

\title{
Epoxy/Silicone Blend Loaded with N-Doped CNT Composites: Study on the Optoelectronic Properties
}

\author{
Younes Ziat $\mathbb{D}^{1},{ }^{1}$ Hamza Belkhanchi $\mathbb{D}^{1,2}$ Maryama Hammi $\mathbb{D}^{1,3}$ and Ousama Ifguis $\mathbb{D}^{4}$ \\ ${ }^{1}$ Engineering and Applied Physics Team (EAPT), Sultan Moulay Slimane University, Beni Mellal, Morocco \\ ${ }^{2}$ Laboratory of Engineering and Applied Technologies, Sultan Moulay Slimane University, Beni Mellal, Morocco \\ ${ }^{3}$ Mohammed 5 University, Rabat, Morocco \\ ${ }^{4}$ Team of Analytical \& Computational Chemistry, Nanotechnology and Environment, Faculty of Science and Technics, \\ Sultan Moulay Slimane University, Beni Mellal, Morocco \\ Correspondence should be addressed to Younes Ziat; ziat.estbm@gmail.com
}

Received 30 June 2021; Revised 5 August 2021; Accepted 28 October 2021; Published 22 November 2021

Academic Editor: Gianluca Coccia

Copyright (C) 2021 Younes Ziat et al. This is an open access article distributed under the Creative Commons Attribution License, which permits unrestricted use, distribution, and reproduction in any medium, provided the original work is properly cited.

\begin{abstract}
Thin films of epoxy/silicone loaded with N-CNT were prepared by a method of sol-gel and deposited on ITO glass substrates at room temperature. The properties of the loaded monolayer samples $(0.00,0.07,0.1$, and $0.2 \mathrm{wt} \% \mathrm{~N}-\mathrm{CNTs})$ were analyzed by UVvisible spectroscopy. The transmittance for the unloaded thin films is $88 \%$, and an average transmittance for the loaded thin film is about 42 to $67 \%$ in the visible range. The optical properties were studied from UV-visible spectroscopy to examine the transmission spectrum, optical gap, Tauc verified optical gap, and Urbach energy, based on the envelope method proposed by Swanepoel (1983). The results indicate that the adjusted optical gap of the film has a direct optical transition with an optical gap of $3.61 \mathrm{eV}$ for unloaded thin films and 3.55 to $3.19 \mathrm{eV}$ for loaded thin films depending on the loading rate. The optical gap is appropriately adapted to the direct transition model proposed by Tauc et al. (1966); its value was $3.6 \mathrm{eV}$ for unloaded thin films and from 3.38 to $3.1 \mathrm{eV}$ for loaded thin films; then, we determined the Urbach energy which is inversely variable with the optical gap, where Urbach's energy is $0.19 \mathrm{eV}$ for the unloaded thin films and varies from 0.43 to $1.33 \mathrm{eV}$ for the loaded thin films with increasing rate of N-CNTs. Finally, nanocomposite epoxy/silicone N-CNT films can be developed as electrically conductive materials with specific optical characteristics, giving the possibility to be used in electrooptical applications.
\end{abstract}

\section{Introduction}

Photovoltaic solar energy is an electrical energy produced from solar radiation by photovoltaic solar cells [1]. This kind of energy is the smartest way to produce electricity, and it has many advantages, such as direct generation of electricity from sunlight $[2,3]$. It is a renewable source and clean $[4-11]$, as well as friendly to the environment $[5,8$, 11-14]. Photovoltaic energy is useful in different applications and devices [15-21].

The prices of the solar cells based on $(\mathrm{Si})$ have declined so speedily that panel expenses now make up $<30 \%$ of the costs of a fully installed "solar-electricity-system" [22]. Because of their fragility, Si thin sheets cannot be treated on their own, but they must be mechanically supported. The researchers proposed to scale thick substrates by adding different materials such as aluminum, silver, nickel, and epoxy [23-26]. They are generally composed of a mixture of inorganic particles embedded in a polymer matrix.

In recent years, the research interest in the development of a new material of polymer-inorganic nanocomposites with improved properties has been very high [27-33], and most research has been directed towards the use of materials in the form of thin films. The nanocomposites allow improving mechanical, electrical, optical, optoelectronic, and magnetic properties. For this reason, many studies have shown that hybrid nanocomposites are used in optoelectronic or optical applications requiring high visible transparency and shielding against ultravisible transparency [34-40].

Today, energetic deposition means are widely used for the manufacture of thin film optical components [41]. These processes allow the fabrication of thin film materials with 
excellent repeatability, whose optical properties are very close to those of the solid material, thus opening doors to higher performance treatments that are insensitive to the constraints of the external environment. This was only possible with the technology developments in thin film deposition using several physical deposition techniques such as reactive sputtering [42], electron beam evaporation [43], and arc deposition $[44,45]$. In particular, the sol-gel method has emerged as one of the most promising processes, as it is economical and efficient in the production of thin films [46, 47] as well as transparent and homogeneous films which are suitable for a variety of substrates. In fact, many works are devoted to this method [48-51]. In this paper, we report a simple and economical method for elaborating thin films of epoxy/silicone blend loaded by nitrogen-doped carbon nanotubes (N-CNTs). The nanocomposites are thin films having interesting optical properties. These films may offer potential new opportunities for photovoltaic applications caused by their specific chemical and electrical properties [52-55].

\section{Experimental Work}

2.1. Material and Methods. The elaborated matrix contains epoxy which is a colorless viscous liquid of $99.9 \%$ purity, supplied along with the hardener from Toronto Research Chemicals and silicone gel from Keol having high purity level (>99\%). The fillers are the nitrogen-doped carbon nanotubes (N-CNTs) which were prepared using physical vapor deposition according to explained protocol in our previous paper [50].

Substrate cleaning is a very important step that takes place in a clean room, as this step determines the adhesion and homogeneity of the deposited layers. The substrates must be free of grease, dust, and scratches. The substrates chosen for our study are blades with Indium Tin Oxide (ITO). The procedure for cleaning the substrates is as follows:

(1) Brushing with detergent, rinsing with deionized water

(2) Ultrasonic cleaning for ten minutes in a beaker filled with detergent

(3) Rinse with deionized water

(4) Ultrasonic cleaning again, but this time in a beaker filled with deionized water, for seven minutes

(5) Steps 3 and 4 are performed three times

(6) Last rinsing with deionized water

(7) Dry at $150^{\circ} \mathrm{C}$ for 15 minutes

First, epoxy and silicone were mixed in a $50 \mathrm{ml}$ beaker with the weight percentage of epoxy which is always kept higher than that of silicone and after a strong stirring, the hardener is added to avoid anisotropy and in order to keep homogeneity. The neat matrix contains $75 \mathrm{wt} \%$ of epoxy, $10 \mathrm{wt} \%$ of silicone, and $15 \mathrm{wt} \%$ of hardeners. Afterward, the N-CNTs were added with weight percent $(0.00,0.07$,
0.1 , and $0.2 \%$ of N-CNTs) in order to obtain homogeneous nanocomposites with consideration that they are formulated using the same process.

The resulting mixture was deposited on the ITO glass substrate at room temperature. The prepared films were thermally cured at 103 for 1 hour then at $115^{\circ} \mathrm{C}$ for $30 \mathrm{~min}$ in the oven to obtain the epoxy/silicone N-CNT films.

2.2. Technical Characterizations. After preparing the thin films of epoxy/silicone N-CNT, microstructural and optical characterizations were carried out, using, respectively, the scanning electron microscopy and UV-visible technique which is based on the property of material and its ability to absorb certain wavelengths of the UV-visible domain. This method determines the transmission $T(\%)$ of a material for a given wavelength $\lambda(\mathrm{nm})$ that has been judiciously chosen. The optical transmission spectrum for the elaborated thin films was registered using a UV-visible spectrophotometer (Jasco V-530) over the wavelength range of $300-800 \mathrm{~nm}$. The microstructure of the processed composite thin films was examined through SEM micrographs which were picked up for epoxy/silicone blend loaded with 0.2 wt\% N-CNTs using FEI Quanta FEG 450 scanning electron microscopy (SEM).

\section{Results and Discussion}

3.1. Optical Properties. Figure 1 shows the transmittance $(T)$ spectrum of the thin films of epoxy/silicone N-CNT as a function of wavelength at room temperature in the spectral range of $300-800 \mathrm{~nm}$. The transmittance spectrum has a high transmittance of up to $88 \%$ in the visible range for neat epoxy/silicone blend, indicating a highly transparent material; it is pointed out that transmittance in the overall wavelength range is considerably reduced with the increased filler content ranging from 0.07 to $0.2 \mathrm{wt} \% \mathrm{~N}-\mathrm{CNT}$.

Figure 1 exhibits a sharp decrease in the optical transmittance around $360 \mathrm{~nm}$; this conduct is observed in many compounds and composites [56, 57]. Also, the optical transmission, the optical band-gap values, and structural and morphological changes of thin films are related to annealing temperature [58] or lamp changing. The optical band-gap values could be varied employing different precursor ions as well as substrate types which will be helpful for a wide variety of optoelectronic applications $[59,60]$

This drastic reduction is caused by significant absorption increasing with the quantity of the N-CNT fillers; this effect is significant in the optimization of the fabrication of the optoelectronic devices. The spectrophotometer allows recording the optical transmission of the layers as a function of wavelength and allows determining the value of the energy of the optical gap $\left(E_{\mathrm{g}}\right)$ of the layer (characteristic of a semiconductor), the refractive index of the films, and their thicknesses. For this aim, we will use the following formulas given by the method of Swanepoel [61]. The thickness of the nanostructures is determined from the following equation:

$$
d=\left(\frac{\lambda_{1} \lambda_{2}}{2\left(\lambda_{1} n_{2}-\lambda_{2} n_{1}\right)}\right)
$$




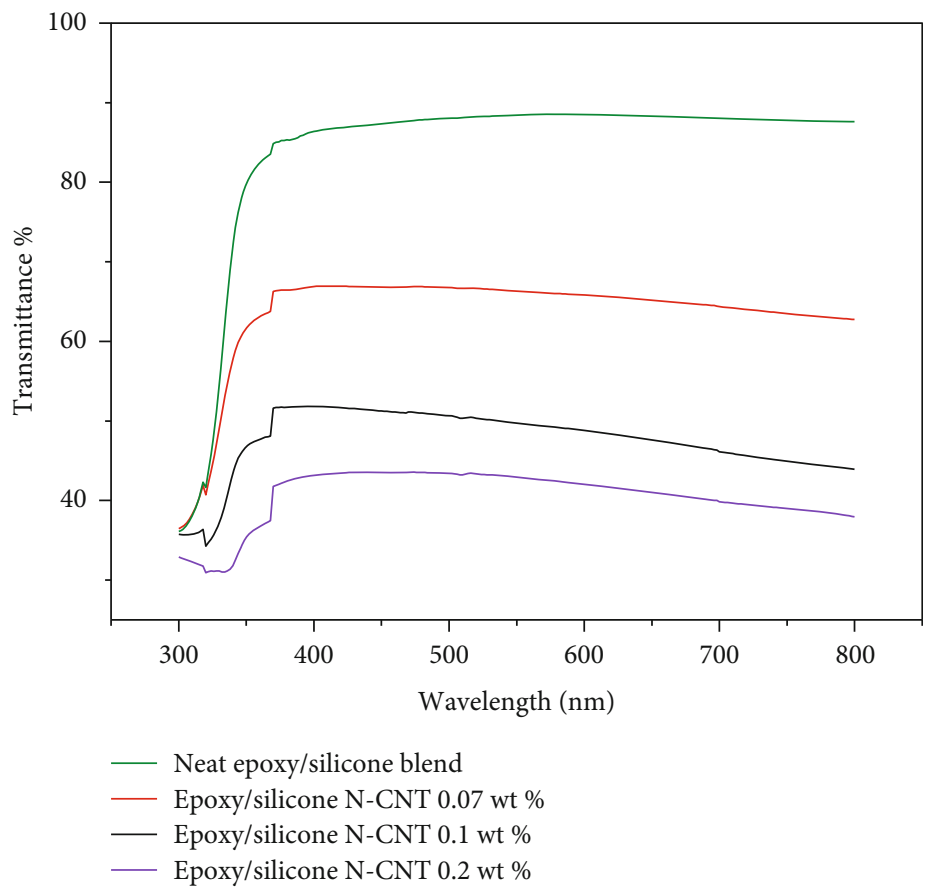

FIGURE 1: Curves of epoxy/silicone film transmission as a function of wavelength for different N-CNT loading rates.

where $n_{1}$ and $n_{2}$ are the refractive indices at two adjacent maxima (or minima) at $\lambda_{1}$ and $\lambda_{2}$. The average values of thickness $d$ of the studied thin films determined by this equation are about $700 \mathrm{~nm}$.

The refractive index in the spectral region of the high, low, and medium absorption zones can be calculated; it follows that the refractive index is given by the following expression:

$$
n_{1}=\left[N_{1}+\left(N_{1}^{2}-S^{2}\right)^{1 / 2}\right]^{1 / 2} n_{2}=\left[N_{2}+\left(N_{2}^{2}-S^{2}\right)^{1 / 2}\right]^{1 / 2} .
$$

In addition, the Swanepoel coefficient $(N)$ in the transparent spectral region can be calculated by the following expression:

$$
\begin{aligned}
& N_{1}=2 S\left(\frac{T_{\max 1}-T_{\min }}{T_{\max 1} \times T_{\min }}\right)+\left(\frac{S^{2}+1}{2}\right), \\
& N_{2}=2 S\left(\frac{T_{\max 2}-T_{\min }}{T_{\max 1} \times T_{\min }}\right)+\left(\frac{S^{2}+1}{2}\right),
\end{aligned}
$$

where $S$ is the refractive index of the glass and $T_{\max }$ and $T_{\min }$ represent the maximum and minimum values for the transmission curve.

The absorption $\alpha$ of the epoxy/silicone N-CNT nanocomposite is linked to transmittance through BouguerLambert-Beer relation [62]:

$$
T=\exp (-\alpha d)
$$

If transmittance $T$ is expressed in \%, the absorption coefficient is shown by

$$
\alpha=\frac{1}{d} \ln \left(\frac{100}{T}\right) .
$$

From the transmittance spectra $(T)$, we can calculate the optical gap value of semiconductors from the Tauc formula $\left(E_{\mathrm{g}}(\mathrm{eV})\right)$ defined by the following equation using [63-67]

$$
(\alpha h v)=B\left(h v-E_{\mathrm{g}}\right)^{n}
$$

The relation can be rewritten in a logarithmic form such as

$$
\ln (\alpha h v)=\ln B+n \ln \left(h v-E_{\mathrm{g}}\right),
$$

where $\alpha$ is the absorption coefficient, $v$ is the absorption frequency, $B$ is constant, $h$ is Planck's constant, and $n$ is dependent on the type of optical transition. The constant $n$ depends on the nature of the optical gap; it is $1 / 2$ for a direct optical gap and 2 for an indirect optical gap.

Note that the interband transitions are accompanied by a change of electronic dynamics. Because the laws of energy and momentum conservation must be satisfied, the indirect electronic band-to-band transitions are phonon-assisted, and phonons must be involved in the electronic interband transition to provide the necessary momentum. Their energetic contribution is negligible if, for instance, the exponent takes the value of $n=2$ [68].

To determine whether the electronic transition that has occurred in the samples studied is direct or indirect, the 
TAble 1: The optical parameters: optical gap $E_{\mathrm{g}}$, power factor $(n)$, Tauc verified $E_{\mathrm{g}}$, and Urbach energy $E_{\mathrm{u}}$ of the studied composite.

\begin{tabular}{|c|c|c|c|c|c|}
\hline \multirow{2}{*}{ Composite } & \multicolumn{3}{|c|}{ Parameters obtained by $(\alpha h v)=B\left(h v-E_{\mathrm{g}}\right)^{n}$} & \multirow{2}{*}{ Tauc verified $E_{\mathrm{g}}(\mathrm{eV})$} & \multirow{2}{*}{ Urbach energy $E_{\mathrm{U}}(\mathrm{eV})$} \\
\hline & $E_{\mathrm{g}}(\mathrm{eV})$ & Factor $(n)$ & Slope $\left(\mathrm{eV} \cdot \mathrm{cm}^{-1}\right)^{1 / n}$ & & \\
\hline Neat epoxy/silicone blend & 3.61 & 0.51 & $4.2010^{8}$ & 3.6 & 0.19 \\
\hline Epoxy/silicone N-CNT 0.07 wt $\%$ & 3.55 & 0.50 & $3.1810^{8}$ & 3.38 & 0.43 \\
\hline Epoxy/silicone N-CNT 0.1 wt\% & 3.42 & 0.54 & $3.2010^{8}$ & 3.3 & 0.61 \\
\hline Epoxy/silicone N-CNT 0.2 wt\% & 3.19 & 0.51 & $2.9810^{8}$ & 3.1 & 1.33 \\
\hline
\end{tabular}

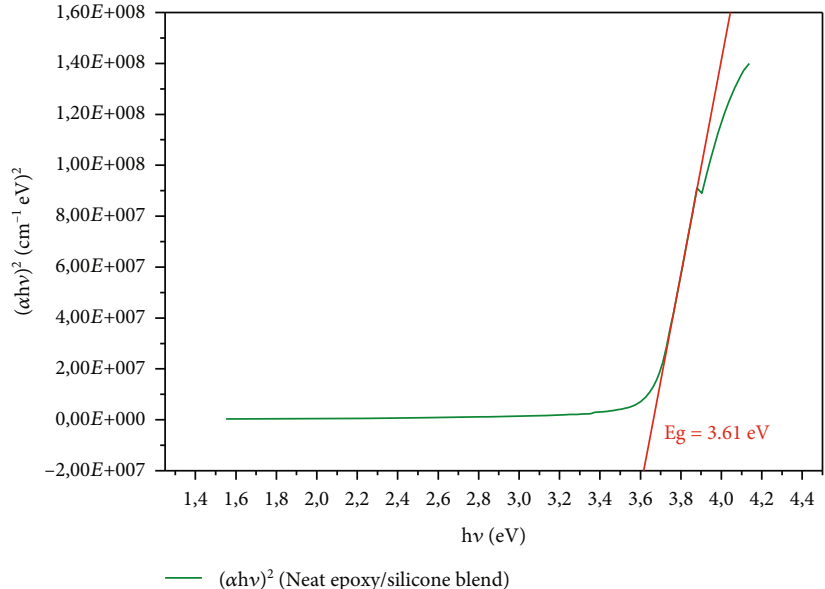

(a)

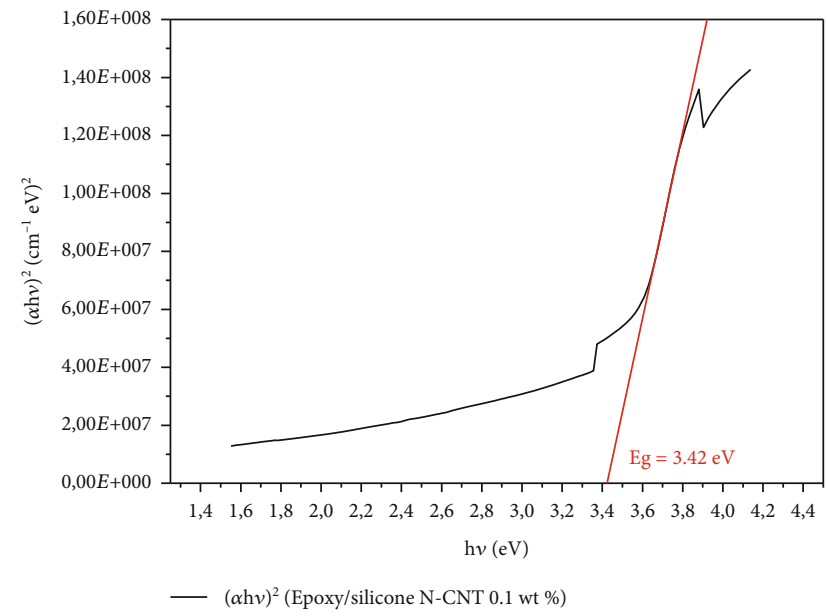

(c)

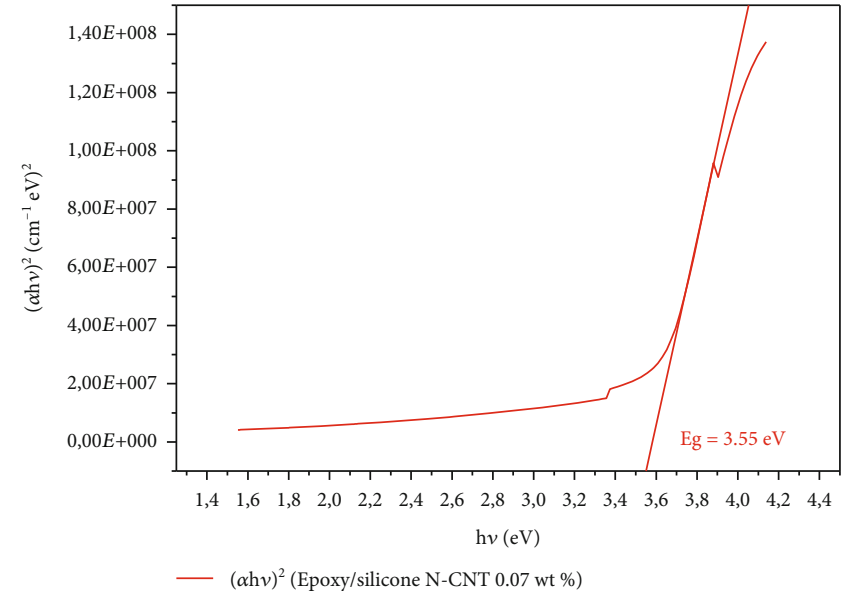

(b)

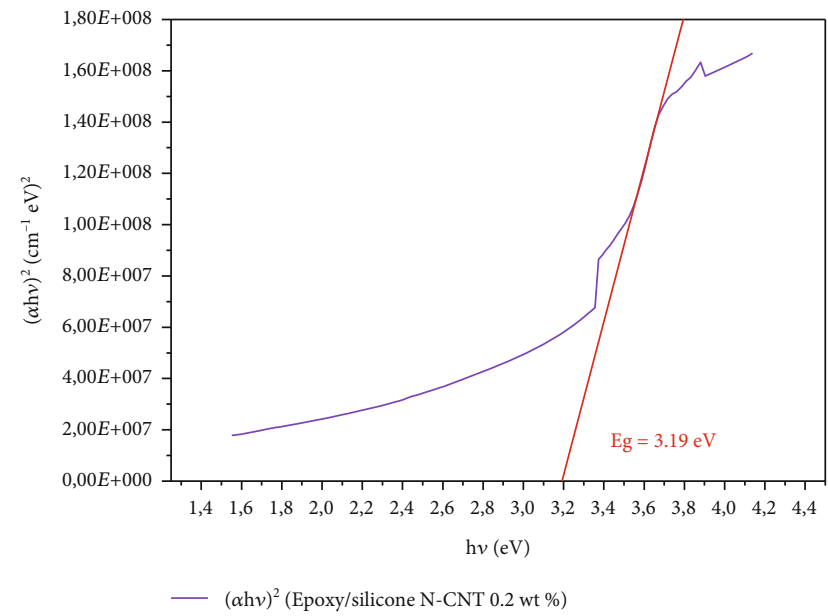

(d)

Figure 2: Plot of $(\alpha h v)^{2}$ versus photon energy $h v$, for “epoxy/silicone N-CNT @ wt\%” (@=0.00, 0.07, 0.1, and 0.2).

optical gap $E_{\mathrm{g}}$ must first be determined using equation (6) to plot $\alpha h v$ versus $h v$; the value of the optical gap is obtained by extrapolating the linear part of the curve, at the intersection of this line with the $x$-axis given in Table 1 ; then, the photon energy $\ln \left(h v-E_{\mathrm{g}}\right)$ is plotted versus $\ln (\alpha h v)$ which has been fitted with equation (7) in the linear region of the curve, using the average-squares method, where $E_{\mathrm{g}}, n$, and $B$ are fitted parameters; this process can show that the type of optical transition of the pure epoxy/silicone mixture is direct with the power factor $n=0.51$, and the same result was obtained for the epoxy/silicone N-CNT w\% loaded.
To verify the validity of the method used, we plotted $(\alpha h v)^{2}$ versus $h v$ as shown in Figure 2 according to the Tauc model [69], giving the value of the direct optical gap. The extrapolation of the linear part of the absorption edge $(\alpha h v)^{2}$ gives the band-gap energy. The use of the power factor $\mathrm{n}$ obtained gives a good agreement between the optical gap bands and the Tauc slopes; almost the same optical gap $E_{\mathrm{g}}$ is found (Table 1), so the correlation between experience and theory is compatible.

Obviously, the optical gap obtained is high for neat epoxy $(3.6 \mathrm{eV})$, because it is optically transparent, and this 


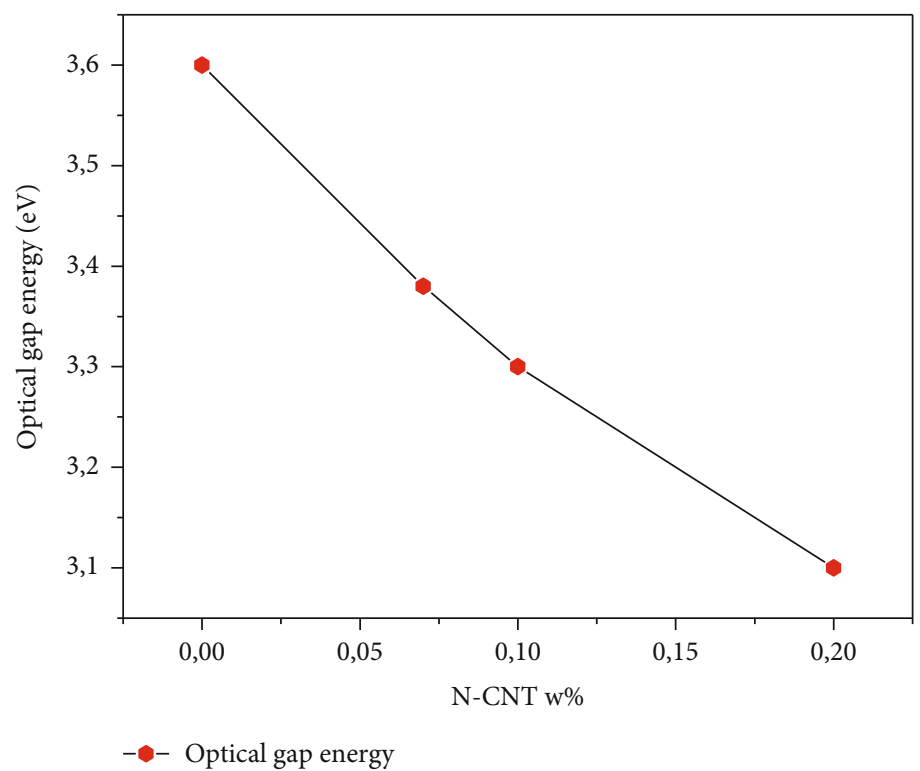

FIgURE 3: Variation of optical gap of epoxy/silicone nanocomposite films versus N-CNT wt\% loaded.

means that no absorption is possible in the visible; they cannot be excited without being loaded with another element to decrease $E_{\mathrm{g}}$, so we load with N-CNT and we see that there is a diminution in $E_{\mathrm{g}}$ in 3.6 to $3.1 \mathrm{eV}$ (Table 1); this decrease of the optical gap with the loading rate is essentially due to the distortions caused in the network following the introduction of impurity (loading) and the increase in the concentration of free electrons; this characteristic would seem to be related to the increase in the number of free carriers with increasing the concentration of nanocomposite loaded in $0.07,0.1$, and 0.2 wt\% N-CNT (Table 1 and Figure 3).

The system is progressively becoming more conducting with addition of N-CNT; this seems to change slightly the structure of the electronic bands of the neat epoxy. In addition, the variation of optical gap with increasing N-CNT loaded concentration can also be correlated with surface roughness and film density. When variations in interatomic distance, length, or angle of bonding are produced in the material, a so-called "disorder" occurs; in this case, the strip edges described in the case of crystalline networks and delimited by valence energy $E_{\mathrm{v}}$ and conduction energy $E_{\mathrm{c}}$ can disappear (Figure 4); so-called localized states formed in band tails at the borders of the optical gap in the valence band and the conduction band are observed.

The forbidden gap is referred to as the pseudogap energy for amorphous semiconductors as in the case of our composites; we note $E_{\mathrm{g}}$. The generation phenomena can only happen if the light energy is larger than the band-gap energy of a semiconductor. For a wide-band-gap semiconductor, this band-gap energy is correspondent to the visible or ultraviolet spectrum excitations. As a consequence, the increase of charge carriers' concentrations in the conduction band may be slight, which maintains that such material type is quite an electrical insulator. The electrical conductivity of amorphous semiconductors can be tuned in several ways. The basic idea is to create free charge carriers (electrons or

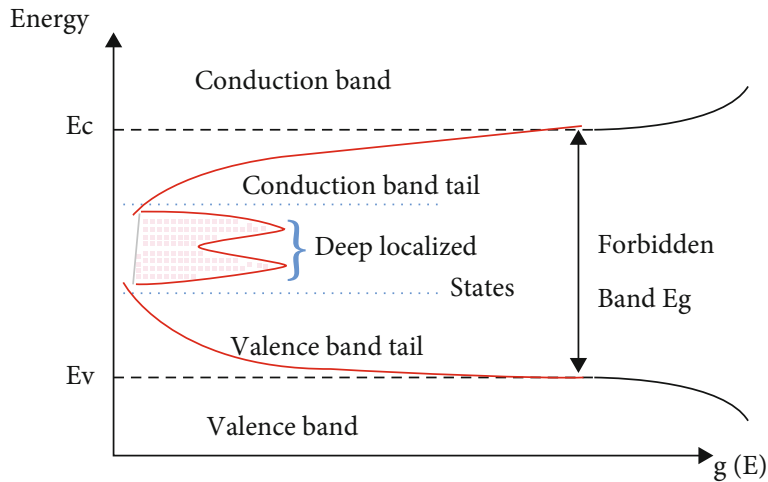

FIGURE 4: Band structure of amorphous semiconductors.

holes) in a wide-band-gap semiconductor through appropriate fillers. This can create extrinsic impurities in the amorphous insulating materials which play a critical role for improving their electrical conductivity. When the disorder becomes too great, with the appearance of dangling links or impurities in the material, one then recalls the notion of Urbach parameter $E_{\mathrm{U}}$ that corresponds to the transition between the extended states of the valence band and the localized states [70]. This phenomenon is exemplified with the absorption coefficient $(\alpha)$ as a function of photon energy near the edge of the band, exhibiting an exponential tail as shown in Figure 5; according to Urbach's law, the expression of the absorption coefficient is of the form [71]

$$
\alpha=\alpha_{0} \exp \left(\frac{h v}{E_{\mathrm{U}}}\right)
$$

where $h$ is Planck's constant, $\alpha_{0}$ is a constant, $v$ is the frequency of absorption, and $E_{\mathrm{U}}$ is Urbach energy. To 


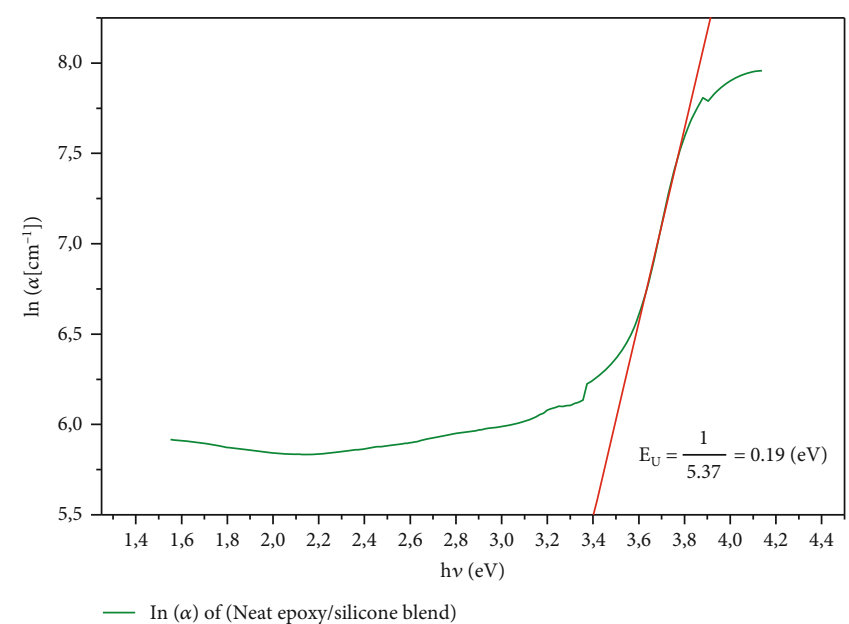

(a)

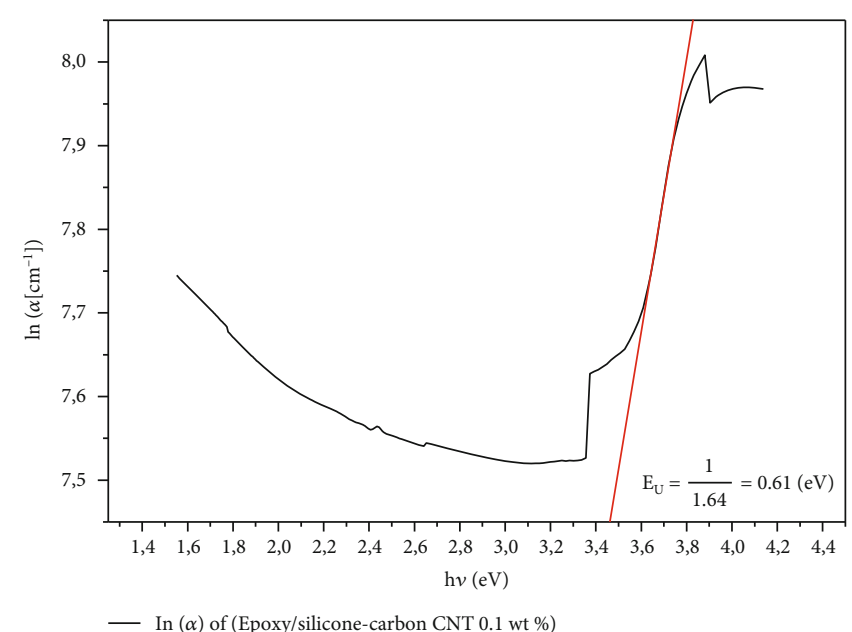

— In $(\alpha)$ of (Epoxy/silicone-carbon CNT $0.1 \mathrm{wt} \%)$

(c)

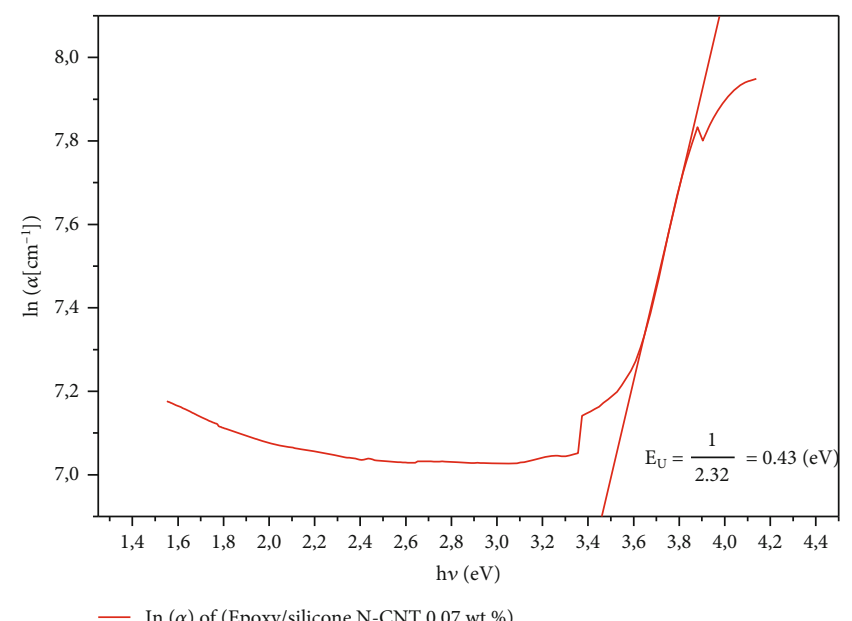

(b)

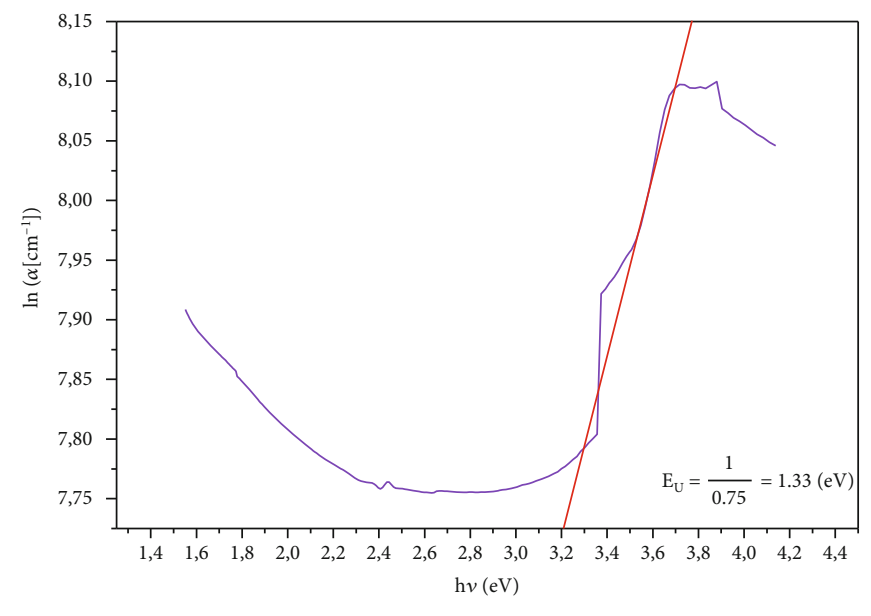

(d)

FIGURE 5: Determination of Urbach energy $E_{U}$ by the plot of $\ln (\alpha)$ versus photon energy $h v$ for “epoxy/silicone N-CNT @ wt \%” (@=0.00, $0.07,0.1$, and 0.2 ).

determine the disorder (Urbach energy) of thin films, we plot the logarithm of $\alpha$ versus of $h v$ :

$$
\ln (\alpha)=\ln \left(\alpha_{0}\right)+\frac{h v}{E_{U}}
$$

It is shown that it is possible to obtain the information on the dynamics of the electronic excitations of condensed matter by Urbach's rule. Thus, Urbach's rule makes it fairly easy to find the degree of the location of the states in the network and to determine the effect of network disorder on the location of the excitement [72].

Figure 5 shows the plot of $\ln (\alpha)$ versus energy $h v$ for a series of thin films of neat epoxy (Figure 5(a)) and epoxy/silicone loaded at different concentrations (Figures 5(b)-5(d)). Therefore, Urbach energy is determined by the reciprocal slope of the adjusted experimental linear behavior; the results of the study are shown in Table 1 . The evolution of the Urbach energy versus the wt\% N-CNT loaded is presented in Figure 5; this figure shows that the Urbach energy values were higher in loaded epoxy/silicone than in the neat, and that the highest value was obtained in the most filled loaded epoxy/silicon.

The increase in tail width can be explained by the creation of disorder and imperfections in the nanocomposite lattice by addition of N-CNT.

The Urbach energy also depends on the optical energy band $E_{\mathrm{g}}$. The Urbach energy increases from 0.19 to $1.33 \mathrm{eV}$ while $E_{\mathrm{g}}$ decreases from 3.6 to $3.1 \mathrm{eV}$ as the amount of NCNT increases (Table 1 and Figure 6).

The variation found in $E_{\mathrm{U}}$ indicates that the N-CNT addition creates a certain disorder, which leads to the structural characterization of the deposits, and the defects are deduced from the Urbach energy exponential absorption tail caused by fluctuations within the matrix optical gap. Moreover, it can be seen that the increase in Urbach's energy opposes the decreasing behavior of the optical gaps with increasing $\mathrm{w} \% \mathrm{~N}-\mathrm{CNT}$ as shown in Figure 6, so Urbach's energy is consistent with the determined values of the optical gap energy. There is also a significant change in slope above 


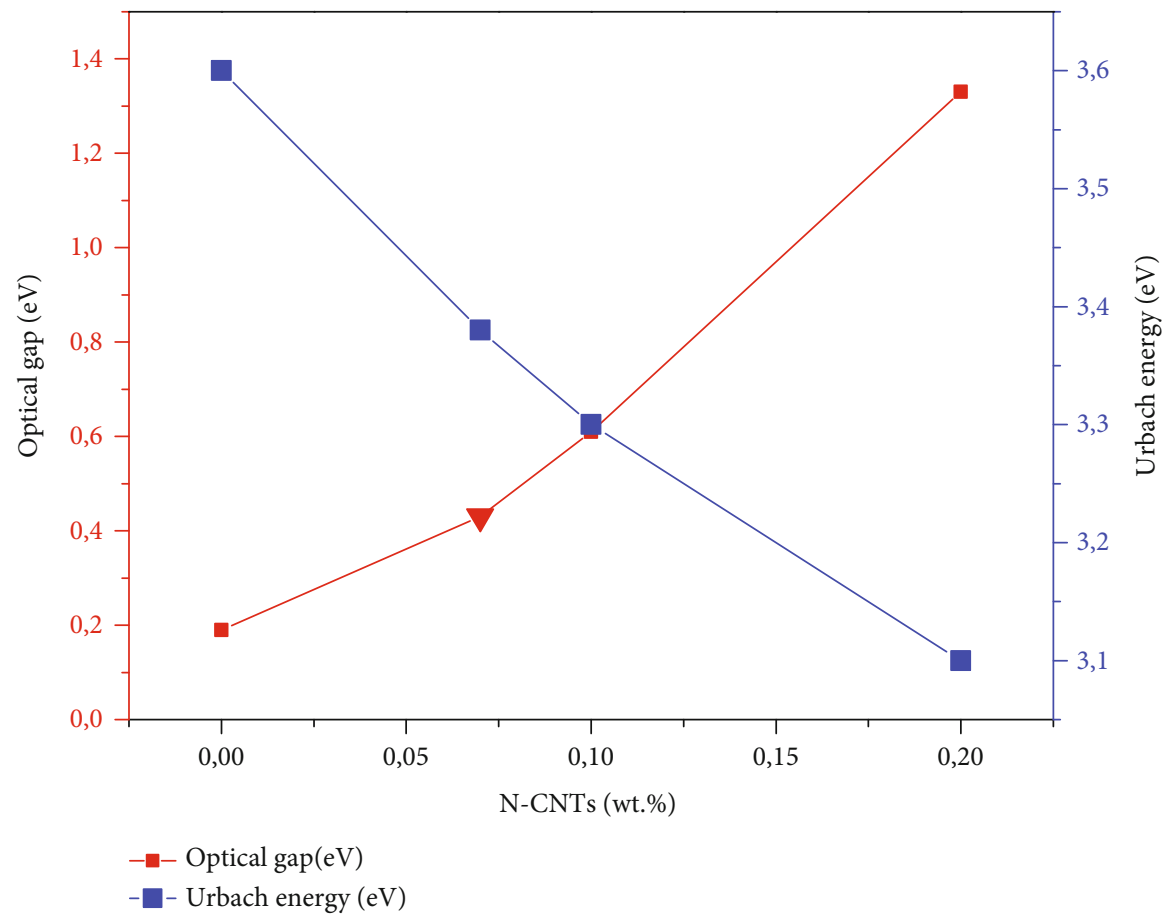

Figure 6: Variation of optical gap and Urbach energy of epoxy/silicone composite films versus wt\% N-CNT.

the percolation threshold, in wt $\% 0.07$ of epoxy/silicone composite film for optical gap and Urbach energy. Indeed, above the percolation threshold, the electron carrier concentration exceeds the density of the conduction band states, the composites become semiconducting, and their number of carriers increases significantly. Therefore, the optical gap must decrease significantly, and the results are in accordance with the theory of Burstein and Moss [73, 74].

3.2. Microstructural Insight. The cured composites exhibited a very dense and relatively smooth surface. The SEM photographs revealed that N-CNT particles were found to be uniformly dispersed throughout the epoxy/silicone blend matrix (Figure 7). This result revealed that there is a good miscibility between the phases, in a good agreement with elsewhere findings [75]. These findings might have a positive impact on electrical conductivities of the studied thin films.

3.3. Electrical Properties of the Fabricated Thin Films. Conductivity is a particular concern for semiconductor materials. Measuring the conductivity of semiconductor films is not that easy as it seems because it depends on a series of inseparable factors, especially temperature. For Urbach energy and optical band gap, the entire curve shows a significant slope change at a specific threshold associated with the epoxy/silicone blendbased composite films. The decrease in $E_{\mathrm{g}}$ and the increase in $E_{\mathrm{U}}$ become faster above this threshold. In order to evaluate this behavior, it is more convenient to measure the relationship between the DC and the change in filler load conductivity at ambient temperature. DC conductivity is based on resistivity measurement. The two-point probe method [76] was used to measure resistivity (it is expressed in $\Omega \cdot \mathrm{cm}$ ) at room temperature (RT). Note that resistivity represents its ability to stop

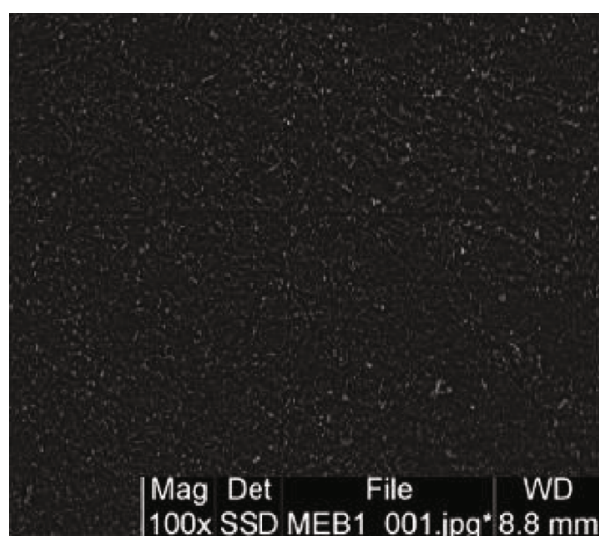

FigURE 7: SEM images of the surface of the thin film with $0.1 \mathrm{wt} \%$ N-CNT.

the flow of current. The resistivity measurement at ambient temperature is performed by plotting the current-voltage characteristics: $I=f(V)$.

The $I=f(V)$ curves are exploited to extract the electrical resistivity. We have measured the electrical resistivity of the studied samples. Then, sheet resistance can be effectively performed utilizing the following equation [77]:

$$
R_{\mathrm{Sh}}=R \cdot \frac{W}{L}
$$

Also, $R=\rho(L / A)=\rho(L / d \cdot W)=(\rho / d) \times(L / W)$ in which

$$
R_{\mathrm{S}}=\frac{\rho}{d},
$$




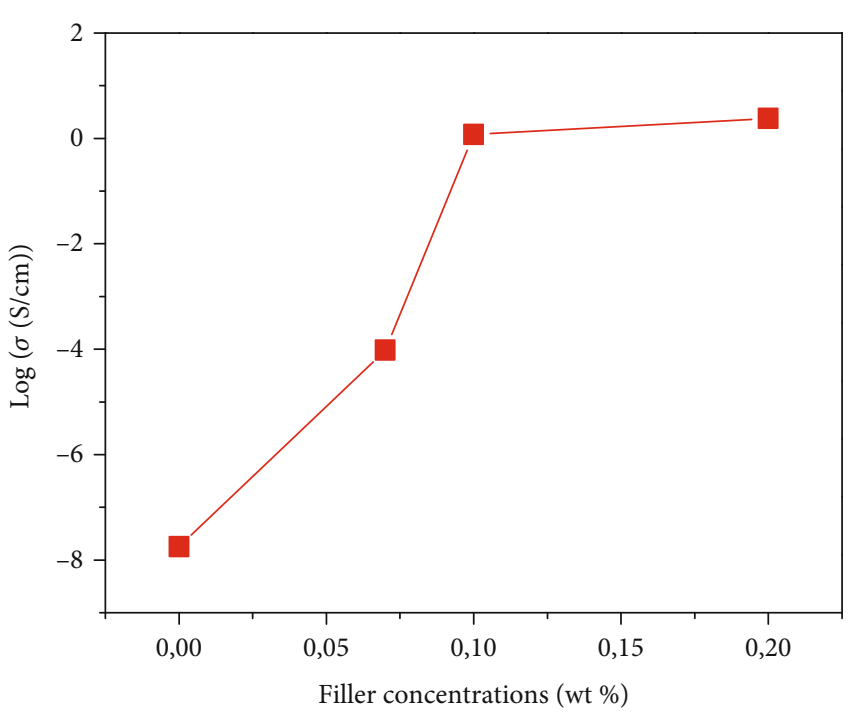

Figure 8: Electrical conductivity of thin films (epoxy/silicone NCNT wt\%) versus conducting filler concentrations.

TABLE 2: Variation of optical figure of merit versus conducting filler concentrations.

\begin{tabular}{lccc}
\hline Material & $\begin{array}{c}\text { Surface } \\
\text { resistance } \\
\left(\Omega / \mathrm{cm}^{2}\right)\end{array}$ & $\begin{array}{c}\text { Visible absorption } \\
\text { coefficient } \alpha\left(\mathrm{cm}^{-1}\right)\end{array}$ & $\begin{array}{c}\text { Figure of } \\
\text { merit }\left(\Omega^{-}\right. \\
\mathrm{cm})\end{array}$ \\
\hline $\begin{array}{l}\text { Neat epoxy/ } \\
\text { silicone blend } \\
\text { Epoxy/silicone }\end{array}$ & 200 & 0.20 & 0.02 \\
$\begin{array}{l}\text { N-CNT } \\
0.07 \text { wt\% }\end{array}$ & 3 & 0.12 & 3 \\
$\begin{array}{l}\text { Epoxy/silicone } \\
\text { N-CNT 0.1 wt\% }\end{array}$ & 3.8 & 0.05 & 5 \\
$\begin{array}{l}\text { Epoxy/silicone } \\
\text { N-CNT 0.2 wt\% }\end{array}$ & 5 & 0.03 & 7 \\
\hline
\end{tabular}

where $\rho$ is the resistivity $(\Omega \cdot \mathrm{cm}), R_{\mathrm{S}}$ is electrical sheet resistance $(\Omega), W$ is the width $(\mathrm{cm}), d$ is the thickness $(\mathrm{cm})$ which can be determined with optical measurements, and Lpresents the length $(\mathrm{cm})$, given that the conductivity is given by $\sigma=1 / \rho$ in $(\Omega \cdot \mathrm{cm})^{-1}$. The curve of DC conductivity behavior versus filler concentrations is represented in the inset of Figure 8.

As indicated in Figure 8, it is worthy to take note that electrical conductivity of unloaded film is about $10^{-8}(\Omega \cdot \mathrm{cm})^{-1}$. It is nonlinearly improved when N-CNT filler content is raised. The fillers give rise then to the electrical conductivity.

3.4. Evaluation of Thin Film Performance through the Calculation of Figure of Merit. The optical and electrical properties of the film are very important properties for all known transparent conductive oxide (TCO) applications. Ideally, a good TCO is identified by the optical transmission coefficient and high electrical conductivity. Therefore, when both light transmission and electrical conductivity are important, the material is considered high performance. These two parameters are inversely proportional and are related by a single factor called the figure of merit (FOM). This later allows reasonable comparisons of film properties and allows estimation of their optoelectronic properties [78]. The films represent a compromise between conductivity and light transmission. The decrease in resistivity involves an increase in the carrier concentration or its mobility. Increasing the number of carriers leads to an increase in absorption. In the present paper, the FOM of the studied films can be evaluated, using the following equation [79]:

$$
\frac{1}{\rho . \alpha}=\frac{\sigma}{\alpha},
$$

where

$$
\mathrm{FOM}=\frac{\boldsymbol{\sigma}}{\mathbf{\alpha}}=-\frac{1}{R_{\mathrm{Sh}} \cdot \ln (T+R)},
$$

where $\boldsymbol{\sigma}$ is the electric conductivity $\left(\Omega^{-1}\right), \boldsymbol{\alpha}$ is the absorption coefficient $\left(\mathrm{cm}^{-1}\right), R_{\mathrm{Sh}}$ is the surface resistance $(\Omega / \mathrm{sq}), T$ is the total transmission (\%), and $R$ is the total reflection (\%). Here, the best FOM is related to good optical transmission and electrical conductivity. It has been shown that useful films must have a FOM greater than or equal to $7[80,81]$. Therefore, considering expression (13), the variation of the FOM value of the studied film with the filler concentration is gathered in Table 2 . We noticed that the figure of merit was improved by increasing the load concentration.

\section{Conclusion}

The optical properties were studied from UV-visible spectroscopy to examine the transmission spectrum, optical gap, Tauc verified gap, and Urbach energy, based on the envelope method proposed by Swanepoel.

The study shows that the films obtained show a high transmittance for the unloaded thin films of neat epoxy/silicone blend about $88 \%$ and an average transmittance for the loaded thin film of epoxy/silicone N-CNT about 42 to $67 \%$ in the visible range and opaque in the UV range.

The results indicate that the film has a direct optical transition with an optical gap of $3.61 \mathrm{eV}$ for unloaded thin films and 3.55 to $3.19 \mathrm{eV}$ for loaded thin films depending on the loading rate. The optical gap was appropriately adapted to the direct transition model proposed by Tauc; its value was $3.6 \mathrm{eV}$ for unloaded thin films and from 3.38 to $3.1 \mathrm{eV}$ for loaded thin films; then, Urbach's energy is determined which is inversely tended with $E_{\mathrm{g}}$ which varies from $0.19 \mathrm{eV}$ for unloaded thin films and from 0.43 to $1.33 \mathrm{eV}$ for loaded thin films. The obtained results show the success of the method sol-gel to elaborate epoxy/silicone loaded with N-CNT films with properties adapted to the physical applications. These results also show that it was possible to modify the loaded epoxy films by inserting a loading. In the near future, this gives hope for applications such like waveguides, electrochemistry, optical fibers, and solar cells. 


\section{Data Availability}

The data used to support the findings of this study are included within the article

\section{Conflicts of Interest}

The authors declare that they have no conflicts of interest.

\section{Acknowledgments}

The authors would like to thank Mrs. Saloua Rzaoudi and Ms. Khadija Ziat for the support. Our thanks are extended to Mr. Mohammed Ali Errachid from "Economy Management, Mohammed 5 University of Rabat, Faculty of Law, Economics and Social Sciences-Souissi, Rabat, Morocco," and Ms. Maryem Errachid from "Universität Paderborn, Warburger Straße 100, 33098 Paderborn, Germany," for accepting the language revision. We are warmly grateful the professor Mohamed Ghaleb from "Lycée Oulad Youssef, Délégation Béni Mellal, Région Béni Mellal-Khénifra, Maroc," for discussing the data of this work. Also, we are grateful to professors Y. Lakhal, FZ. Baghli, M. Benchagra, A. Balouki, M. Aqil, and A. Boudaoud who are the founders of "Engineering and Applied Physics Team (EAPT) of Sul$\tan$ Moulay Slimane University, Beni Mellal, Morocco," for the fruitful discussion and the provided expertise. A special thanks is addressed to professor Abderrahmane Amhirik from "Faculty of Arts and Humanities, Beni Mellal, Morocco," for the valuable propositions.

\section{References}

[1] P. G. V. Sampaio and M. O. A. González, "Photovoltaic solar energy: conceptual framework," Renewable and Sustainable Energy Reviews, vol. 74, pp. 590-601, 2017.

[2] W. Hoffmann, "PV solar electricity industry: market growth and perspective," Solar Energy Materials \& Solar Cells, vol. 90, no. 18-19, pp. 3285-3311, 2006.

[3] K. Q. Peng and S. T. Lee, "Silicon nanowires for photovoltaic solar energy conversion," Advanced Materials, vol. 23, no. 2, pp. 198-215, 2011.

[4] J. L. Silveira, C. E. Tuna, and W. Q. Lamas, "The need of subsidy for the implementation of photovoltaic solar energy as supporting of decentralized electrical power generation in Brazil," Renewable and Sustainable Energy Reviews, vol. 20, pp. 133-141, 2013.

[5] J. Peng, L. Lu, and H. Yang, "Review on life cycle assessment of energy payback and greenhouse gas emission of solar photovoltaic systems," Renewable and Sustainable Energy Reviews, vol. 19, pp. 255-274, 2013.

[6] T. Bhattacharya, A. K. Chakraborty, and K. Pal, "Effects of ambient temperature and wind speed on performance of monocrystalline solar photovoltaic module in Tripura, India," Journal of Solar Energy, vol. 2014, Article ID 817078, 5 pages, 2014.

[7] H. Kim, E. Park, S. J. Kwon, J. Y. Ohm, and H. J. Chang, “An integrated adoption model of solar energy technologies in South Korea," Renewable Energy, vol. 66, pp. 523-531, 2014.

[8] M. Hosenuzzaman, N. A. Rahim, J. Selvaraj, M. Hasanuzzaman, A. B. M. A. Malek, and A. Nahar, "Global prospects, progress, policies, and environmental impact of solar photovoltaic power generation," Renewable and Sustainable Energy Reviews, vol. 41, pp. 284-297, 2015.

[9] Z. Lan and J. Li, "Photovoltaic technology and electricity saving strategies for fixed-velocity-measuring system," TELKOMNIKA Indonesian Journal of Electrical Engineering, vol. 12, no. 6, pp. 4419-4426, 2014.

[10] G. Liu, "Sustainable feasibility of solar photovoltaic powered street lighting systems," International Journal of Electrical Power \& Energy Systems, vol. 56, pp. 168-174, 2014.

[11] N. S. Lewis, "Introduction: solar energy conversion," Chemical Reviews, vol. 115, no. 23, pp. 12631-12632, 2015.

[12] L. el Chaar, L. A. lamont, and N. el Zein, "Review of photovoltaic technologies," Renewable and Sustainable Energy Reviews, vol. 15, no. 5, pp. 2165-2175, 2011.

[13] V. V. Tyagi, N. A. A. Rahim, N. A. Rahim, and J. A. L. Selvaraj, "Progress in solar PV technology: research and achievement," Renewable and Sustainable Energy Reviews, vol. 20, pp. 443461, 2013.

[14] J. Mundo-Hernández, B. de Celis Alonso, J. Hernández-Álvarez, and B. de Celis-Carrillo, "An overview of solar photovoltaic energy in Mexico and Germany," Renewable and Sustainable Energy Reviews, vol. 31, pp. 639-649, 2014.

[15] B. Parida, S. Iniyan, and R. Goic, "A review of solar photovoltaic technologies," Renewable and Sustainable Energy Reviews, vol. 15, no. 3, pp. 1625-1636, 2011.

[16] R. W. Miles, K. M. Hynes, and I. Forbes, "Photovoltaic solar cells: an overview of state-of-the-art cell development and environmental issues," Progress in Crystal Growth and Characterization of Materials, vol. 51, no. 1-3, pp. 1-42, 2005.

[17] R. W. Miles, "Photovoltaic solar cells: choice of materials and production methods," Vacuum, vol. 80, no. 10, pp. 10901097, 2006.

[18] R. W. Miles, G. Zoppi, and I. Forbes, "Inorganic photovoltaic cells," Materials Today, vol. 10, no. 11, pp. 20-27, 2007.

[19] A. Zahedi, "Solar photovoltaic (PV) energy; latest developments in the building integrated and hybrid PV systems," Renewable Energy, vol. 31, no. 5, pp. 711-718, 2006.

[20] S. Mekhilef, R. Saidur, and A. Safari, "A review on solar energy use in industries," Renewable and Sustainable Energy Reviews, vol. 15, no. 4, pp. 1777-1790, 2011.

[21] V. Devabhaktuni, M. Alam, S. Shekara Sreenadh Reddy Depuru, R. C. Green II, D. Nims, and C. Near, "Solar energy: trends and enabling technologies," Renewable and Sustainable Energy Reviews, vol. 19, pp. 555-564, 2013.

[22] N. S. Lewis, "Research opportunities to advance solar energy utilization,” Science, vol. 351, no. 6271, 2016.

[23] R. Niepelt, J. Hensen, A. Knorr, V. Steckenreiter, S. KajariSchroder, and R. Brendel, "High-quality exfoliated crystalline silicon foils for solar cell applications," Energy Procedia, vol. 55, pp. 570-577, 2014.

[24] R. Ramadan, M. Manso-Silván, and R. J. Martín-Palma, "Hybrid porous silicon/silver nanostructures for the development of enhanced photovoltaic devices," Journal of Materials Science, vol. 55, no. 13, pp. 5458-5470, 2020.

[25] S. W. Bedell, D. Shahrjerdi, B. Hekmatshoar et al., "Kerf-Less removal of $\mathrm{Si}, \mathrm{Ge}$, and III-V layers by controlled spalling to enable low-cost PV technologies," IEEE Journal of Photovoltaics, vol. 2, no. 2, pp. 141-147, 2012.

[26] R. Martini, M. Gonzalez, F. Dross et al., "Epoxy-induced spalling of silicon,” Energy Procedia, vol. 27, pp. 567-572, 2012. 
[27] M. S. Wang and T. J. Pinnavaia, "Clay-polymer nanocomposites formed from acidic derivatives of montmorillonite and an epoxy resin," Chemistry of Materials, vol. 6, no. 4, pp. 468-474, 1994.

[28] E. P. Giannelis, "Polymer layered silicate nanocomposites," Advanced Materials, vol. 8, no. 1, pp. 29-35, 1996.

[29] J. Wu and P. T. Mather, "POSS polymers: physical properties and biomaterials applications," Polymer Reviews, vol. 49, no. 1, pp. 25-63, 2009.

[30] A. Strachota, P. Whelan, J. Kriz et al., "Formation of nanostructured epoxy networks containing polyhedral oligomeric silsesquioxane (POSS) blocks," Polymer, vol. 48, no. 11, pp. 3041-3058, 2007.

[31] Q. Li, L. Chen, M. R. Gadinski et al., "Flexible hightemperature dielectric materials from polymer nanocomposites," Nature, vol. 523, no. 7562, pp. 576-579, 2015.

[32] C. Sanchez and B. Lebeau, "Design and properties of hybrid organic-inorganic nanocomposites for photonics," MRS Bulletin, vol. 26, no. 5, pp. 377-387, 2001.

[33] R. Mangal, S. Srivastava, and L. A. Archer, "Phase stability and dynamics of entangled polymer-nanoparticle composites," Nature Communications, vol. 6, no. 1, 2015.

[34] A. Thabet, Y. A. Mobarak, and M. Bakry, "A review of nanofillers effects on industrial polymers and their characteristics," Engineering Sciences, vol. 39, pp. 377-403, 2011.

[35] L. Shanghua, M. L. Meng, S. T. Muhammet, K. K. Do, and M. Mamoun, "Nanocomposites of polymer and inorganic nanoparticles for optical and magnetic applications," Nano Reviews, vol. 1, no. 1, p. 5214, 2010.

[36] S. Kango, S. Kalia, A. Celli, J. Njuguna, Y. Habibi, and R. Kumar, "Surface modification of inorganic nanoparticles for development of organic- inorganic nanocomposites-A review," Progress in Polymer Science, vol. 38, no. 8, pp. 12321261, 2013.

[37] X. Y. Huang, H. R. Heulings IV, V. Le, and J. Le, "Inorganic -organic hybrid composites containing MQ (II-VI) slabs: a new class of nanostructures with strong quantum confinement and periodic arrangement," Chemistry of Materials, vol. 13, no. 10 , pp. $3754-3759,2001$.

[38] W. Caseri, "Inorganic nanoparticles as optically effective additives for polymers," Chemical Engineering Communications, vol. 196, no. 5, pp. 549-572, 2008.

[39] H. Althues, J. Henle, and S. Kaskel, "Functional inorganic nanofillers for transparent polymers," Chemical Society Reviews, vol. 36, no. 9, pp. 1454-1465, 2007.

[40] P. M. Ajayan, L. S. Schadler, and P. B. Braun, Nanocomposite Science and Technology, Wiley, Weinheim, Germany, 2003.

[41] H. A. Macleod, "Recent developments in deposition techniques for optical thin films and coatings," in Optical Thin Films and Coatings, pp. 3-25, Woodhead Publishing Limited, USA, 2013.

[42] D. Mardare and P. Hones, "Optical dispersion analysis of $\mathrm{TiO}_{2}$ thin films based on variable-angle spectroscopic ellipsometry measurements," Materials Science and Engineering: B, vol. 68, no. 1, pp. 42-47, 1999.

[43] T. Modes, B. Scheffel, C. Metzner, O. Zywitzki, and E. Reinhold, "Structure and properties of titanium oxide layers deposited by reactive plasma activated electron beam evaporation," Surface and Coatings Technology, vol. 200, no. 1-4, pp. 306-309, 2005.
[44] M. Zhang, G. Lin, C. Dong, and L. Wen, "Amorphous $\mathrm{TiO}_{2}$ films with high refractive index deposited by pulsed bias arc ion plating," Surface and Coatings Technology, vol. 201, no. 16-17, pp. 7252-7258, 2007.

[45] Z. Zhao, B. K. Tay, and G. Yu, "Room-temperature deposition of amorphous titanium dioxide thin film with high refractive index by a filtered cathodic vacuum arc technique," Optical Society of America, vol. 43, no. 6, pp. 1281-1285, 2004.

[46] K. Bouras, G. Schmerber, D. Aureau et al., "Photon management properties of $\mathrm{Yb}$-doped $\mathrm{SnO}_{2}$ nanoparticles synthesized by the sol-gel technique," Physical Chemistry Chemical Physics, vol. 21, no. 38, pp. 21407-21417, 2019.

[47] S. Šegota, L. Ćurković, D. Ljubas, V. Svetličić, I. F. Houra, and N. Tomašić, "Synthesis, characterization and photocatalytic properties of sol-gel $\mathrm{TiO}_{2}$ films," Ceramics International, vol. 37, no. 4, pp. 1153-1160, 2011.

[48] A. A. I. Khalil, A.-S. H. M. Abd El-Gawad, and A.-S. Gadallah, "Impact of silver dopants on structural, morphological, optical, and electrical properties of copper-zinc sulfide thin films prepared via sol-gel spin coating method," Optical Materials, vol. 109, 2020.

[49] M. N. Kamalasanan and S. Chandra, "Sol-gel synthesis of $\mathrm{ZnO}$ thin films," Thin Solid Films, vol. 288, no. 1-2, pp. 112-115, 1996.

[50] H. Belkhanchi, Y. Ziat, M. Hammi et al., "Nitrogen doped carbon nanotubes grafted $\mathrm{TiO}_{2}$ rutile nanofilms: Promising material for dye sensitized solar cell application," Optik, vol. 229, 2021.

[51] H. Belkhanchi, Y. Ziat, M. Hammi et al., "Synthesis of N-CNT/ TiO2composites thin films: surface analysis and optoelectronic properties," E3S Web of Conferences, vol. 183, 2020.

[52] C. P. Ewels and M. Glerup, "Nitrogen doping in carbon nanotubes," Journal of Nanoscience and Nanotechnology, vol. 5, no. 9, pp. 1345-1363, 2005.

[53] G. Ciric-Marjanovic, I. Pasti, and S. Mentus, "One-dimensional nitrogen-containing carbon nanostructures," Progress in Materials Science, vol. 69, pp. 61-182, 2015.

[54] Y. Zhang, J. Zhang, and D. S. Su, "Substitutional doping of carbon nanotubes with heteroatoms and their chemical applications," ChemSusChem, vol. 7, no. 5, pp. 1240-1250, 2014.

[55] M. Terrones, A. Jorio, M. Endo et al., "New direction in nanotube science," Materials Today, vol. 7, no. 10, pp. 30-45, 2004.

[56] L. Liang, Y. Sheng, Y. Xu, D. Wu, and Y. Sun, "Optical properties of sol-gel derived $\mathrm{ZrO}_{2}-\mathrm{TiO}_{2}$ composite films," Thin Solid Films, vol. 515, no. 20-21, pp. 7765-7771, 2007.

[57] D. Zhang, K. Yang, Y. Li et al., "Employing $\mathrm{TiO}_{2}$ buffer layer to improve $\mathrm{VO}_{2}$ film phase transition performance and infrared solar energy modulation ability," Journal of Alloys and Compounds, vol. 684, pp. 719-725, 2016.

[58] F. Lekoui, R. Amrani, W. Filali et al., "Investigation of the effects of thermal annealing on the structural, morphological and optical properties of nanostructured $\mathrm{Mn}$ doped $\mathrm{ZnO}$ thin films," Optical Materials, vol. 118, 2021.

[59] W. Ismail, M. Bakry, M. Elshobaki, A. El-Shaer, and M. Abdelfatah, "Impact of precursor concentrations and substrate type on properties of electrodeposited $\mathrm{CdO}$ nanorod thin films for optoelectronic applications," Materials Science in Semiconductor Processing, vol. 133, 2021.

[60] W. A. Wani, S. Kundu, K. Ramaswamy, and H. Venkataraman, "Structural, morphological, optical and dielectric investigations in cobalt doped bismuth ferrite 
nanoceramics prepared using the sol-gel citrate precursor method," Journal of Alloys and Compounds, vol. 846, 2020.

[61] R. Swanepoel, "Determination of the thickness and optical constants of amorphous silicon," Journal of Physics E: Scientific Instruments, vol. 16, no. 12, pp. 1214-1222, 1983.

[62] K. Lagha-Menouer, Étude et réalisation d'une cellule solaire multicouches du type $\mathrm{Si}-\mathrm{SiO}_{2}-\mathrm{SnO}_{2}-\mathrm{ZnO}$ par APCVD, M. Mammeri, Ed., Tizi-Ouzou University, Algeria, 2011.

[63] J. Tauc and A. Menth, "States in the gap," Non-Crystalline, vol. 8-10, pp. 569-585, 1972.

[64] Y. Ziat, A. Abbassi, A. Slassi et al., "First-principles investigation of the electronic and optical properties of Al-doped $\mathrm{FeS}_{2}$ pyrite for photovoltaic applications," Quantum Electronics, vol. 48, no. 11, 2016.

[65] A. Benyounes, N. Abbas, M. Hammi, Y. Ziat, A. Slassi, and N. Zahra, "Fabrication and characterization of novel transparent conducting oxide N-CNT doped $\mathrm{ZnO}$ for photovoltaic applications," Applied Physics A, vol. 124, no. 2, 2018.

[66] Z. Zarhri, M. Á. Cardos, Y. Ziat et al., "Synthesis, structural and crystal size effect on the optical properties of sprayed $\mathrm{TiO}_{2}$ thin films: experiment and DFT TB-mbj," Alloys and Compounds, vol. 819, 2020.

[67] M. Hammi, Y. Ziat, A. A. Raiss et al., "Effect of Fe doping on the electronic structure, optical and electrical properties of $\mathrm{ZnO}$ compound: ab initio insights," Optik, vol. 131, pp. 399405, 2017.

[68] B. Pejova, B. Abay, I. Bineva, and F. Bo, "Temperature dependence of the band-gap energy and sub-band-gap absorption tails in strongly quantized ZnSe nanocrystals deposited as thin films," The Journal of Physical Chemistry C, vol. 114, no. 36, pp. 15280-15291, 2010.

[69] J. Tauc, R. Grigorovici, and A. Vancu, "Optical properties and electronic structure of amorphous germanium," Physica Status Solidi, vol. 15, no. 2, pp. 627-637, 1966.

[70] A. Moustaghfir, Élaboration et caractérisation de couches minces d'oxyde de zinc. Application à la photoprotection du polycarbonate. Matériaux, Université Blaise PascalClermont-Ferrand II, Français, 2004.

[71] F. Urbach, "The long-wavelength edge of photographic sensitivity and of the electronic absorption of solids," American Physical Society, vol. 92, p. 1324, 1953.

[72] I. Studenyak, M. Kranj, and M. Kurik, "Urbach rule in solid state physics," International Journal of Optics, vol. 4, 83 pages, 2014.

[73] E. Burstein, "Anomalous optical absorption limit in InSb," American Physical Society, vol. 93, no. 3, pp. 632-633, 1954.

[74] T. S. Moss, "The interpretation of the properties of indium antimonide," Proceedings of the Physical Society, vol. 67, no. 10, pp. 775-782, 1954.

[75] K.-H. Wu, K.-F. Cheng, C.-C. Yang, C.-P. Wang, and C.-I. Liu, "Thermal and optical properties of epoxy/siloxane hybrimer based on sol-gel-derived phenyl-siloxane," Open Journal of Composite Materials, vol. 5, no. 3, pp. 49-59, 2015.

[76] Y. Singh, "Electrical resistivity measurements: a review," International Journal of Modern Physics: Conference Series, vol. 22, pp. 745-756, 2013.

[77] J. Domaradzki, D. Kaczmarek, K. Drabczyk, and P. Panek, "Investigations of electrical and optical properties of functional TCO thin films," Materials Science-Poland, vol. 33, no. 2, pp. 363-368, 2015.
[78] S. Faÿ, L'oxyde de zinc par dépôt chimique en phase vapeur comme contact électrique transparent et diffuseur de lumière pour les cellules solaires, Ecole polytechnique Fédérale de Lausanne (EPFL scientific publications), Lausanne, Switzerland, 2003.

[79] O. S. Heavens, Optical Properties of Thin Solid Films, Dover, New York, NY, USA, 1965.

[80] R. G. Gordon, "Criteria for choosing transparent conductors," MRS Bulletin, vol. 25, no. 8, pp. 52-57, 2000.

[81] N. F. Mott and E. A. Davis, Electronic Process in Noncrystalline Materials, Clarendon Press, Oxford, 1971. 